\title{
A GESTÃO ESCOLAR DEMOCRÁTICA E O PRINCÍPIO DE VALORIZAÇÃO E RECONHECIMENTO DO TRABALHO DO PROFESSOR
}

DOI: $10.5902 / 2318133832901$

\author{
Maria Lúcia Leite da Silva \\ Débora Ortiz de Leão \\ Universidade Federal de Santa Maria, Brasil.
}

\begin{abstract}
Resumo
Neste texto tem-se a intenção de ampliar as reflexões sobre a relação da gestão escolar e a valorização dos professores. Para tanto, partiu-se do seguinte questionamento: como uma gestão escolar democrática pode influenciar o reconhecimento e valorização do professor na escola pública? Compreendeu-se que ao trazer a comunidade para dentro da escola, especialmente nos eventos organizados em reuniões pedagógicas, valorizar as iniciativas dos professores e outras ações que auxiliam no desenvolvimento de uma educação de qualidade, os gestores demonstraram a sua compreensão sobre a importância de uma gestão escolar democrática e o seu reconhecimento ao trabalho dos professores.

Palavras-chave: gestão escolar democrática; valorização dos professores; reconhecimento ao trabalho dos professores.
\end{abstract}

\section{DEMOCRATIC SCHOOL MANAGEMENT AND THE PRINCIPLE OF VALUING AND RECOGNITION OF TEACHER'S WORK}

\begin{abstract}
This work arises intending to broaden the reflections about the relation of the school management and the teachers valuing. For that, it started from the following question: how a democratic school management can influence the recognition and teacher's valuing in the public school? It was understood that by bringing the community into the school, especially in the events organized in pedagogic meetings, to value the initiatives of the teachers and other actions that help in the development of a high-level education, the managers demonstrated their understanding on the importance of a democratic school management and its recognition of teachers' work.

Key-words: democratic school management; teachers valuing; recognition of teachers' work.
\end{abstract}




\section{Introdução}

- ste texto teve origem na monografia de final do curso de especialização em Gestão Educacional da Universidade Federal de Santa Maria e foi pensado a partir da minha participação nos últimos dez anos num grupo de pesquisa sobre formação continuada de professores.

Nos encontros nesse grupo sempre fizemos leituras e também reflexões sobre o que é ser professor, o que é a formação profissional, bem como sobre a estrutura escolar. As teorias estudadas foram confrontadas com observações feitas durante estágio curricular, na participação em projetos de alfabetização em escolas municipais com alunos de $1^{\circ}$ a $6^{\circ}$ anos do ensino fundamental, onde foi possível observar diferentes modelos de gestão escolar. Igualmente, participei como professora em escolas de educação infantil particular. Estas, embora com um perfil totalmente diferenciado das escolas públicas, também enfrentam muitas dificuldades e desafios.

Finalmente, atuei em uma turma de Educação Infantil em uma escola municipal, onde havia poucas reuniões pedagógicas e, nestas reuniões, eram tratados mais as indisciplinas dos alunos, reunião de pais, eventos e entrega de bilhetes. Os professores não conseguiam chegar a um consenso sobre os conteúdos que deveriam ser desenvolvidos. A partir desta perspectiva percebi a necessidade de uma investigação que possibilitasse reformas e oportunidades de melhorias na gestão do pedagógico.

Entendo que, na escola, o aluno precisa ser visto a partir de suas necessidades individuais de aprendizagem e não apenas como mais um integrante deste contexto. Essa mudança depende da organização cultural implantada na instituição escolar. Apesar de a escola ser uma instituição de cunho social e ter como objetivo o aprendizado dos alunos, a mesma precisa ser direcionada para a realização das suas metas. É necessário ter um planejamento pedagógico, bem como, administrativo e financeiro. Desta forma, precisamos compreender a atuação da gestão dentro da escola e qual a sua influência nos resultados no ambiente escolar.

Sendo assim, esse trabalho teve como problema: como uma gestão democrática pode influenciar o reconhecimento e valorização do professor na escola pública? O objetivo geral foi compreender a influência de uma gestão democrática no reconhecimento e valorização do trabalho do professor na escola pública.

\section{Gestão democrática}

Ao pensar em melhorar a qualidade da educação não podemos apenas analisar a parte pedagógica, curricular e estrutural. Precisamos avaliar alternativas que construam laços de solidariedade, respeito e momentos de encontro de formação e conhecimento do que é uma escola, como ela é estruturada para a comunidade escolar, envolvendo seus atores. Ou seja, que toda a comunidade escolar se sinta amada e acarinhada ao chegar à escola. Mas, para isso, é necessário que gestores escolares façam um trabalho focando estes pontos com toda a comunidade escolar.

Estas reflexões aumentam na medida em que questiono minha própria atuação como coordenadora de uma escola particular. Neste período um dos maiores desafios encontrados foi a dificuldade de aprendizagem dos alunos e a atuação dos professores, 
que divergiam do planejamento da escola. Sabendo das responsabilidades da gestão escolar, precisamos nos preocupar com a cultura organizacional e o enfrentamento de desacordos pessoais existentes no ambiente escolar.

Uma das particularidades que ocasionam as contradições dentro da escola é o não conhecimento por parte de todos os profissionais da educação sobre as leis e normativas que envolvem o funcionamento escolar.

Conforme a lei n. 4.740, de 24 de dezembro de 2003, que institui a gestão escolar democrática no município de Santa Maria,

a autonomia pedagógica será assegurada pela implantação por parte de cada escola de seu projeto político-pedagógico, elaborado com a participação da comunidade escolar, em consonância com as políticas públicas vigentes e as normas do sistema municipal de ensino.

Parágrafo único - A Secretaria de Município da Educação deverá oferecer condições e recursos humanos para implementação do projeto político pedagógico. (Santa Maria, 2003).

Estas leis existem, mas precisam ser estudadas, bem como ser acompanhadas de uma cobrança dos órgãos competentes, para que sejam executadas: "Qualquer profissional da educação que seja compromissado com fazer pedagógico e político não pode deixar que o conhecimento de tais constrangimentos normativos seja competência de quem exerce funções administrativas" (Cury, 2004, p. 44). Sendo assim, o bom funcionamento da escola também depende do envolvimento de todos os componentes, cada um fazendo a sua parte, se sentindo valorizado e responsável pelo bom andamento da escola. Por isso a gestão democrática refere-se à partilha de responsabilidades, conhecimentos e tomada de decisão, entre outros, para que haja um bom andamento escolar.

A gestão democrática em uma escola tem um sentido amplo, necessitando que na elaboração do projeto político-pedagógico conste um diálogo da comunidade escolar com a comunidade externa, para que haja um maior crescimento na educação. Neste sentido, Lück (2011) ressalta que

a gestão na escola, corresponde a dar vez e voz e envolver na construção e implementação do seu projeto político-pedagógico a comunidade escolar como um todo: professores, funcionários, alunos, pais e até mesmo a comunidade externa da escola, mediante uma estratégia aberta de diálogo e construção do entendimento de responsabilidade coletiva pela educação. (p. 81)

É importante, também, que tanto a parte administrativa, quanto a financeira e a pedagógica fiquem descentralizadas. Com isto, cada integrante pode se sentir parte desta comunidade. Segundo Bruno (2008), "ao mesmo tempo, é necessária uma participação maior dos sujeitos envolvidos no processo educacional no interior da escola, na exata medida em que suas responsabilidades aumentam com a descentralização operacional" (p. 40). Cada integrante da escola precisa acreditar no seu potencial para que haja o crescimento e desenvolvimento coletivo. Um dos maiores desafios é atingir os objetivos almejados pelo projeto político-pedagógico e organizar o planejamento diário, de forma participativa. Para Libâneo, Oliveira e Toschi (2007), o "sistema de organização e de 
gestão da escola é o conjunto de ações, recursos, meios e procedimentos que propiciam as condições para alcançar esses objetivos" (p. 315). Com isso, é preciso investigar as oportunidades de melhorias neste ambiente, revendo processos e planejamentos com o intuito de harmonizar as relações sociais e alcançar os objetivos da escola, assim como, participar de grupo de pesquisa sobre a formação continuada de professores, com leituras feitas que levem a refletir mais sobre o ser professor, como está o nosso preparo profissional e nos faça pensar a respeito da estrutura escolar.

A valorização do professor na escola pública poderá ser influenciada e reconhecida com uma gestão educacional democrática. Portanto, a partir deste estudo procurar-se-á definir o sentido de gestão. O que se observa é uma direção responsável por tomar todas as decisões, não existindo muitas vezes a coordenação pedagógica e muito menos reuniões pedagógicas, quando na realidade, a escola precisa ter uma gestão que articule recursos a alcançar o que ela pretende mediante ações construídas em conjunto com a comunidade escolar:

Em vista disso, o necessário reforço que se dá à gestão visa, em última instância, a melhoria das ações e processos educacionais, voltados para a melhoria da aprendizagem dos alunos e sua formação, sem o que aquela gestão se desqualifica e perde a razão de ser. (Lück, 2011, p. 15)

Dentro deste contexto parte-se para uma gestão educacional, em que o educador necessita trazer a sua prática unida ao conhecimento adquirido juntamente com 0 conhecimento das políticas públicas. O gestor precisa sair da sua área de conforto e proporcionar formação a todas as escolas que a mesma abrange, bem como verificar em determinado tempo como está o andamento do conhecimento que foi desenvolvido. Para Gutierrez e Catani (2013) "a escola pública acaba lidando com o Brasil real, o Brasil da miséria, da pobreza em todos os sentidos, de uma forma muito mais direta e urgente que a universidade ou a empresa" (p. 83).

A gestão democrática é de suma importância para nossas escolas, pois observa-se a falta de um trabalho construído em conjunto com toda a comunidade escolar. Cada ator participante precisa sentir-se valorizado e fazer parte de todo o contexto existente. Aprendemos com as diferenças quando deixamos tempo para que as mesmas consigam se adaptar. Gutierrez e Catani (2013) defendem que "a incorporação bem sucedida de pessoas em qualquer organização depende de um período de adaptação, durante o qual o novo elemento conhece e adota padrões típicos de comportamento" (p. 80).

É de suma importância que cada elemento do grupo consiga ultrapassar a cultura autoritária que está enraizada no seu eu, na sua aprendizagem bem como no conhecimento das políticas públicas e vá a procura de um conhecimento mais crítico. De acordo com Gutierrez e Catani (2013),

a superação da formação autoritária e burocrática de cada um, só pode ser bem-sucedido porque a realidade que nos cerca é essencialmente contraditória, ou seja, ao mesmo tempo em que se convive com políticas conservadoras e violentas que induzem à infantilização das pessoas, também assistimos a experiências progressistas, principalmente nos campos da educação, cultura e sociabilidade espontânea, que incentivam a participação responsável dentro de grupos com posturas críticas, 0 amadurecimento moral e o autoconhecimento. (p. 81) 
Toda a gestão escolar necessita de uma elaboração coletiva do PPP. O mesmo precisa ser construído pela equipe diretiva, professores, funcionários, pais e a comunidade. A construção deste projeto é de suma importância, exigindo muita paciência e também são necessárias várias reuniões pedagógicas.

A gestão democrática na escola é construída não só pelo diretor, pois é composta de ações e decisões fazendo com que o diretor seja liderança e não simplesmente aquele que toma atitudes. Durante o dia a dia, o diretor ou equipe diretiva se deparam com várias situações que não compete só a ele resolver. Quando é só o diretor para resolver os problemas, fica mais difícil do que quando a escola tem uma gestão democrática, pois não será só ele a encontrar solução para o problema. A gestão democrática é um processo onde a eleição para diretor garante a democracia como prática escolar e o momento que acontece a tomada de decisão de toda a comunidade escolar e o diretor entende a escola como instituição pedagógica.

Desta forma, em uma gestão educacional democrática é imprescindível um PPP elaborado por toda a comunidade escolar, é necessário que a Secretaria Municipal de Educação libere mais reuniões pedagógicas, bem como um planejamento participativo, onde, inclusive, os alunos possam opinar. O objetivo seria fazer com que os mesmos se envolvam no processo educativo, diminuindo a evasão escolar.

\section{Formação de professores}

Quando pensamos em formação de professores, dentro de todo este contexto, é de suma importância que os gestores conheçam a história de vida de cada membro da comunidade escolar e a sua caminhada acadêmica. Quando se fala em caminhada acadêmica, nos referimos desde a entrada na graduação até a sala de aula como profissional. Neste período, os educadores e gestores necessitam aprimorar os seus conhecimentos com criatividade, fazendo com que o aluno que se sinta atraído pelo conhecimento e tenha prazer de vir para a escola. Do contrário, aos poucos, o fracasso escolar começará a ser sentido pela comunidade. Gatti (1996), ressalta que

a gestão e os gestores da educação têm que desenvolver novas perspectivas e saber implementá-las, a menos que se queira eternizar 0 fracasso escolar e inviabilizar nosso avanço social, que só se concretizará com a democratização da distribuição do conhecimento sistematizado a parcelas mais amplas da população. (p. 8)

Para se fazer frente a esse desafio, durante a graduação, o conhecimento teórico deverá ser enriquecido com a experiência junto às escolas e através da participação em eventos. Também nos cursos a distância observa-se esta deficiência na cultura acadêmica. Os estudantes de pós-graduação e também os professores que já atuam em escolas com uma carga horária de quarenta horas, bem como muitos deles estão sem contato com novos conhecimentos a um bom tempo necessitando de muito esforço para recuperar-se e não desistir. Nota-se uma certa resistência no uso de tecnologias da informação: "esses professores trabalharão com crianças em tenra idade e com a alfabetização, o que exige uma formação delicada, um aprendizado de relações pessoais, pedagógicas, didáticas, de formas de linguagem específicas" (Gatti, 2014, p. 38). 
Quanto à formação de professores, tem sido um grande desafio para as políticas educacionais. Inúmeros países desenvolvem políticas e ações agressivas na área educacional cuidando, sobretudo, dos formadores, ou seja, dos professores, que são os personagens centrais e mais importantes na disseminação do conhecimento e de elementos substanciais da cultura. Devemos nos reportar aos anos 1970, quando foi dado início às mudanças na política educacional, com denúncias a respeito da crise que estava chegando à educação, tanto no que se refere ao trabalho como salários dignos.

Balzan (1985) procura explicar essa degeneração do sistema educacional brasileiro. De acordo com o autor, isso aconteceu a partir do final dos anos 1960 e início da década de 1970, quando houve uma valorização ao máximo da educação no discurso governamental acompanhada de uma significativa redução dos recursos públicos destinados ao setor de uma maneira geral.

Já no final da década de 1980 as mudanças se direcionaram mais para a formação continuada de professores. Num primeiro momento apareceram críticas com os chamados cursos de treinamento e reciclagem oferecidos aos professores das instituições superiores de ensino. Acontece que a criação destes cursos foi insuficiente, aconteciam esporadicamente e na sua maioria não eram pensados nas necessidades dos professores. Nóvoa (1992) declara que

a formação não se constrói por acumulação (de cursos, de conhecimentos ou de técnicas), mas sim através de um trabalho de reflexividade crítica sobre as práticas e de (re)construção permanente de uma identidade pessoal. Por isso é tão importante investir na pessoa e dá um estatuto ao saber da experiência. (p. 25)

Também é de suma importância que a formação continuada traga mudanças a toda escola, de nada adianta o professor ir acumular conhecimento e não o aplicar em sala de aula muito menos ser passado nas reuniões pedagógicas, para que outros colegas usufruam deste conhecimento. Segundo Nóvoa (1992), as escolas não podem mudar sem o empenho dos professores e estes não podem mudar sem uma transformação das instituições em que trabalham, pois "o desenvolvimento profissional dos professores tem que estar articulado com as escolas e seus projetos" (Nóvoa, 1992, p. 28).

O professor necessita estar em constante busca de novos conhecimentos para que a sua prática não se torne obsoleta e sem atrativo algum para o aluno. Também no seu dia-a-dia necessita fazer reflexões a respeito da sua prática após cada turno de aula. Da mesma forma, o professor tem que entender que ele não é dono do saber e que com um simples olhar ou palavra ele pode desmotivar o educando fazendo com que o mesmo se sinta mais angustiado frente às dificuldades que tem na aprendizagem. Paulo

O professor, para fazer uma formação continuada, em primeiro lugar precisa de uma transformação do seu eu, mas para isso precisa aprender a trocar as suas experiências, as suas aprendizagens e saber interagir com o todo. Moita (1995), deixa bem claro que

ninguém se forma no vazio. Formar-se supõe troca, experiência, interações sociais, aprendizagens, um sem fim de relações. Ter acesso ao modo como cada pessoa é, ter em conta a singularidade da sua história e sobretudo o modo singular como age, reage e interage com o seu contexto. (p. 115) 
Todo o professor necessita trabalhar a sua autoestima para que a mesma não enfraqueça e ao mesmo tempo não fique na espera das respostas de outros para sentirem-se valorizados e que ao participarem dos cursos de formação continuada saibam questionar que as temáticas oferecidas muitas vezes estão distantes da realidade da escola. Antunes (2005) mostra que

o processo de desvalorização profissional, desconhecimento da memória docente e o descrédito em relação a produção de saberes e fazeres docentes acabam contribuindo para o enfraquecimento da auto-estima do professor e conseqüentemente para a má qualidade de ensino na sala de aula. (p. 28)

Assim, esse processo nos leva a refletir, segundo Antunes (2005), que é a partir de ações tomadas no sistema educacional e dos demais gestores que a mudança acontece, pois são eles que devem buscar a valorização da memória docente e das aprendizagens acumuladas de suas experiências e é onde acontecerá o equilíbrio da teoria e prática, do contrário o professor começará a diminuir a autoestima trazendo junto à má qualidade de suas aulas.

\section{Valorização do professor e história de vida}

Observo que na nossa carreira de professor cada vez mais diminui os jovens que entram na graduação e que vão atuar nas escolas. Os que chegam ao final de carreira se aposentam e os novos ao ingressarem por via de concurso deparam-se com alunos em vulnerabilidade social e falta de limites. Assim, na sua maioria, não sabem como lidar com as diversas situações existentes. Isto acontece pela formação oferecida pelos cursos em si, estrutura escolar, estrutura do sistema e pela situação salarial. Gatti (2000), enfatiza que

boa proporção daqueles que declaram sua preferência pelo exercício do Magistério manifestam apreensão quanto a realmente permanecer nessa profissão, condicionando isto a conseguirem uma posição mais estável e definida, aspecto sobre o qual levantam também dúvidas pelas informações que têm sobre a forma como seu trabalho é considerado, tanto no setor público como no privado. (p. 59)

A Emenda Constitucional n. 59/2009 (Brasil, 2009) mudou a condição do Plano Nacional de Educação, que passou por uma transição da Lei de Diretrizes e Bases da Educação Nacional, lei n. 9.394/1996 (Brasil, 1996) para uma exigência constitucional com periodicidade decenal, significando que os planos plurianuais devem ser tomados como referência. Diante disto foi criada a meta 17 onde valoriza os profissionais do magistério das redes públicas de educação básica, fazendo com que haja uma equiparação dos rendimentos com os demais profissionais que tenham escolaridade equivalente, até o final do sexto ano de vigência deste PNE (Brasil, 2014).

Os cursos de graduação deveriam mudar os seus procedimentos e metodologias e atualizá-los. Gatti (2000) salienta que 
a capacidade básica a ser desenvolvida seria a de ensinar, subsidiada pelas habilidades de compreender os alunos situadamente, selecionar e utilizar procedimentos de ensino, elaborar e utilizar procedimentos de avaliação, de interação com as crianças, de estabelecimento de objetivos contextualizados. Um mínimo de inserção na cultura geral também se faz necessário. (p. 47)

Da mesma forma, os cursos deveriam ter em sua matriz curricular, desde o início, a presença nas escolas. Estar presente na escola fará com que o futuro profissional adquira mais conhecimentos e uma experiência mais rica e madura. Gatti (2000) afirma que "ensinar é uma prática complexa, ainda mais nas condições de desigualdade social que o professor enfrenta face a seus alunos e das diferentes condições de escolarização com que tem de lidar no sistema" (p. 41). Sobre essa questão, Libâneo (1986) explica que a prática pedagógica é

uma prática social envolvendo uma inter-relação adultos-aprendizes observada a fase de desenvolvimento psicológico e social destes últimos e que visa a modificações profundas nos sujeitos envolvidos a partir de aprendizagem de saberes existentes na cultura, conduzida de tal forma a preencher necessidades e exigências de transformação da sociedade. ( $p$. 43)

Por estar atuando sempre em escola, tomando conhecimento de como ela é organizada no seu dia a dia, vejo a importância de quando sugerida uma ideia, ela ser aceita pela gestão da escola. Ideias como a aquisição de material lúdico que trabalhe a motricidade fina e ampla entre tantos outros, trazer brincadeiras em uma data específica, jogos entre as turmas, palestras com temas que os professores tenham conhecimento que a turma está precisando e que tenham atividades lúdicas e concretas. Outros pontos positivos é a relação afetiva conquistada em sala de aula tanto com os pequenos como com os adolescentes. Gatti (2000) expressa que "no que respeita ao que os professores acham mais gratificantes no Magistério, o referido estudo mostra que a grande maioria diz serem as atividades de sala de aula e as boas relações afetivas no trabalho" (p. 62).

Quando Catani (1998) afirma que ao colaborar de alguma forma para que esses profissionais reinventassem suas próprias práticas e soubessem refletir sobre as mesmas ela nos remete a idéia de que hoje como nos deparamos com alunos em vulnerabilidade social, nada melhor do que achar maneiras mais motivadoras de expor os conteúdos que são destinados. Portanto, o desafio de uma gestão é compreender cada um dos professores e suas histórias de vida.

\section{Metodologia}

A pesquisa teve uma abordagem metodológica relacionada com a pesquisa qualitativa, envolvendo direção e coordenação da educação infantil e anos iniciais de uma escola municipal. Optar por uma pesquisa qualitativa significa que toda a comunidade escolar necessita apropriar-se de dados que se apresente, como vivem cada família e que conhecimentos as mesmas têm, bem como o espaço físico em que moram. Para Flick (2009) 
a pesquisa qualitativa usa o texto como material empírico (em vez de números), parte da noção da construção social das realidades em estudo, está interessada nas perspectivas dos participantes, em suas práticas do dia a dia e em seu conhecimento cotidiano relativo a questão em estudo. (p. 16)

Foi utilizado um questionário semiestruturado, contendo três questões como instrumento de coleta de dados. Também precisamos partir para a pesquisa participativa na busca de melhorias na comunidade escolar, mas sem intenção de que tudo esteja solucionado. Campos (1984), nos remete a ideia "de que a pesquisa participante reserva inúmeras possibilidades para o estudo da escola, sempre que não seja entendida como solução mágica, definitiva ou conclusiva" (p. 66). Após a devolução dos questionários pelos gestores, foi realizada a análise com destaque para os aspectos principais de cada resposta. A seguir, serão apresentadas as reflexões possíveis neste momento a partir desse material.

\section{Análises e discussões}

Além do questionário foram relatadas algumas situações que demonstraram o papel de uma gestão democrática na condução de ações com a participação da comunidade escolar.

\section{Primeiro relato de experiência na escola}

Observei que a direção, em conjunto com os pais, acordou em reunião que os alunos das séries iniciais não ficariam em posse dos celulares nas salas de aula. A maneira que a equipe diretiva organizou foi que fizessem no computador os números das salas, depois colassem em sacos plásticos tamanho ofício que ao ser dado o sinal para início do turno, a diretora e o vice-diretor fazem entrega para os líderes de cada turma. Quando chegam às salas depois de recolhidos todos os celulares, o líder vai até a sala da direção e faz a entrega. O celular que for visto pela professora em sala de aula será entregue à direção que chamará o responsável para entregar. No final do turno, faltando cinco minutos para o sinal, os líderes vão até a direção, recolhem os celulares entregam aos colegas e vão devolver os sacos plásticos na direção.

Apesar de, em um primeiro momento parecer uma atitude estranha, dada a ampla e irrestrita utilização desses aparelhos nos dias atuais, se pode perceber que, nesse caso, houve um acordo entre as partes: gestores, professores, pais e alunos. A decisão conjunta sobre os impasses ainda é a melhor maneira para resolver possíveis conflitos em um ambiente escolar.

\section{Segundo relato de experiência na escola}

Durante a semana da Páscoa conversei com a direção na possibilidade de conseguir brinquedos de recreação - piscina de bolinhas, escorregador, etc. - para as crianças da educação infantil se divertir no último dia de aula que antecedeu o domingo da Páscoa. Fiquei muito feliz quando a professora Flávia veio até a minha sala e disse que tinha como conseguir e me deu o valor, respondi a ela que não tinha problema nenhum e que visse e desse o retorno. A seguir, voltou e falou que tinha conversado com a diretora na possibilidade de dividir com as turmas dos pequenos da tarde. Enfim, tudo 
resolvido, as professoras aceitaram a parceria e a escola também. A professora Flavia conseguiu piscina de bolinhas, dois cavalinhos e escorregador. Na sexta-feira, a manhã foi diferente, fomos para a sala de vídeo, onde a equipe da recreação montou os brinquedos. Os pequenos amaram, brincaram felizes toda manhã, ao saírem entreguei a lembrancinha que fiz para cada um.

O relato dessa situação demonstra como pode ocorrer a valorização das iniciativas dos professores na escola. Com simples atitudes se pode encontrar formas de valorização profissional no ambiente escolar e demonstrar respeito e consideração aos saberes docentes. $O$ respeito às idéias trazidas pelos professores, o diálogo e a parceria que se constrói em torno de uma atividade recreativa, por exemplo, são mecanismos importantes para consolidar uma gestão democrática e participativa na escola.

$\mathrm{Na}$ sequência, apresento as questões que foram entregues aos professores que fazem parte da direção e coordenação pedagógica de uma escola pública da cidade de Santa Maria/RS:

1. Que atitudes uma gestão democrática pode tomar no sentido de reconhecer e valorizar os professores da escola?

2. Como avaliam o sucesso ou não das propostas democráticas de reconhecimento e valorização do professor?

3. Como percebem o envolvimento dos professores na escola e na aprendizagem dos alunos?

Após a devolução dos questionários foi realizada a análise de cada resposta, com destaque para os aspectos principais que poderiam contribuir para enriquecer as reflexões sobre o tema e os objetivos propostos anteriormente nesse trabalho.

Ao responder a primeira pergunta, que tem como palavra-chave 'atitudes' no sentido de reconhecer e valorizar o professor, o gestor $A$, ressaltou as reuniões pedagógicas onde as decisões são tomadas no grande grupo, o diálogo de forma participativa, as comemorações que homenageiam cada profissional e as datas festivas que são publicadas no Facebook da escola bem como as práticas inovadoras e criativas dos professores e também o dia do planejamento que é quinzenal, por Lei teria que acontecer semanal.

O gestor B relatou um clima amigável, um relacionamento flexível e aberto a críticas e sugestões. Organiza as reuniões pedagógicas para que os professores se sintam acolhidos e respeitados, podendo respeitar suas opiniões e angústias, além de trocar experiências e compartilhar conhecimento. Sempre que possível atende aos pedidos e ouve as angústias dos professores, tentando auxiliá-los a resolver os conflitos ou promover uma reunião para que sejam encontradas formas de buscar o melhor caminho para a questão. Oportuniza momentos entre os professores. Este gestor vê uma gestão mediadora no relacionamento professor-aluno-comunidade, principalmente quando surgem conflitos. O trabalho do professor deve ser acima de tudo considerado primordial e as atitudes e metodologias precisam ser compreendidas em seu contexto. Os materiais necessários ao trabalho devem estar sempre à disposição, as salas de aula limpas, iluminadas e em boas condições de trabalho. 
O gestor $\mathrm{C}$ mencionou as reuniões pedagógicas semanais nas quais são ouvidos os anseios e planejam as atividades no coletivo. A escola tenta, dentro de suas possibilidades estruturais, dar um suporte pedagógico com os materiais e equipamentos necessários para o trabalho docente, sala e espaço educativo em condições.

O gestor $\mathrm{D}$ vê uma gestão democrática na escola quando valoriza os professores, melhora as condições de trabalho, incentiva os professores a fazerem cursos de formação, atualização, valoriza os projetos e trabalhos desenvolvidos em sala de aula, respeita-os como ser humano e como profissional, une os turnos em atividades do mesmo turno, bem como os dois turnos da escola.

Nas respostas a essa primeira pergunta, percebe-se que, apesar de cada gestor ter o seu próprio olhar, eles comungam das mesmas ideias no sentido de reconhecer e valorizar os professores por meio de atitudes ou ações de divulgação dos trabalhos das práticas criativas. Os gestores procuram disponibilizar recursos para os trabalhos dos professores em sala de aula. Outra forma de valorizar o trabalho do professor seria melhorar o ambiente da sala de aula, paredes pintadas, ar condicionado em condições de funcionamento.

Além dessas ações os gestores investem na formação de professores, por meio de cursos, pois acreditam que a formação continuada é extremamente importante para promover mudanças na escola.

Com isso, quer dizer que mesmo com as ações de valorização como estas, existem conflitos, problemas de interpretação que algumas vezes dificultam uma gestão democrática.

Nas respostas relativas à segunda pergunta, sobre como os gestores avaliam o sucesso ou não das propostas de reconhecimento e valorização do professor, o gestor $A$, informou que pelo próprio envolvimento do professor reconhecido e dos outros do grupo a fim de cada vez se empenharem mais. Isso se evidencia na própria fala dos professores, como a da professora do segundo, que certo dia disse que procura sempre fazer um pouquinho mais, pois sempre que precisa a escola está a disposição e reconhece o seu trabalho. Observa-se nas propostas lançadas nas reuniões e como o grupo encara e se envolve opinando e participando.

O gestor B respondeu que observa conforme o bom andamento das atividades, o rendimento dos alunos no convívio com os professores, nas conversas com alunos, durante as reuniões com os pais, etc.

O gestor $\mathrm{C}$ informou que observa nas reuniões pedagógicas e nos diálogos diários com os professores onde através de suas falas nos remetem a atender seus anseios, não dependem da gestão financeira ou das políticas publicas colocadas na escola. Também é necessário avaliar e encontrar caminhos que satisfaçam a demanda.

O gestor $\mathrm{D}$ mencionou que seria no dia a dia em conversas, reuniões com o grupo ou individualmente procurando saber como o professor está, se consegue desenvolver seu projeto, suas idéias.

Isso significa que uma gestão democrática necessita estar atenta às demandas do grupo e sensível aos desejos, gestos e sentimentos que envolvem um trabalho coletivo em uma escola. Afinal, são pessoas de diferentes características, faixas geracionais e culturas diversas envolvidas em um mesmo espaço, em prol de um mesmo objetivo que é a qualidade da aprendizagem e desenvolvimento integral dos alunos. 
Com relação à terceira pergunta, que questionava o envolvimento dos professores na escola e na aprendizagem dos alunos, o gestor $A$ informou que é pelo planejamento dos professores, suas propostas/práticas construídas em sala de aula e o próprio resultado dos alunos.

O gestor $\mathrm{B}$ respondeu que é no dia a dia da escola, nas atividades de sala de aula, nas conversas com os alunos, no rendimento dos mesmos, nas propostas extraclasse, nos projetos bem como na participação em eventos, durante as reuniões pedagógicas, etc.

O gestor $\mathrm{C}$ informou que isso é percebido pelas manifestações, no encontros diários, nas exposições dos trabalhos, nos resultados das aprendizagens, no envolvimento dos trabalhos quando solicitados.

O gestor $D$ responder que pelo envolvimento dos professores na escola percebemos quando eles se comprometem com as atividades propostas, participando dos eventos, dando opiniões quanto o andamento da escola.

Sendo assim, os gestores percebem o envolvimento dos professores e a aprendizagem dos alunos quando há um bom relacionamento entre aluno e professor e quando os alunos estão obtendo sucesso na avaliação, além de observarem também os aspectos citados anteriormente. Neste sentido, Sacristán (1995) ressalta que "o ensino é uma prática social, não só porque se concretiza na interação entre professores e alunos, mas também porque estes atores refletem a cultura e contextos sociais a que pertencem" (p. 66). Com isso, quero ressaltar a importância da cultura local, onde cada escola está inserida para um bom andamento de uma gestão escolar democrática.

\section{Considerações finais}

A partir do estudo bibliográfico realizado, das análises dos fatos observados e das respostas dos questionários foi possível reconhecer que a gestão na escola em que foi realizada a pesquisa de campo, contempla a concepção de gestão democrática no que diz respeito ao reconhecimento e a valorização do professor na escola pública. No entanto, temos que ter em mente que a qualidade de aprendizagem dos alunos em uma escola não é apenas decorrente da questão pedagógica, curricular ou estrutural. São todos esses aspectos reunidos, procurando sempre chegar a um ponto em comum e, que este traga a melhor aprendizagem ao educando. Também é necessário trazer a comunidade que se instala ao redor da escola, as famílias dos alunos e demonstrar tudo o que é trabalhado com os mesmos, bem como, os investimentos na infraestrutura e o que está acontecendo de melhorias para os educandos.

É na elaboração do PPP que aparece a realidade da comunidade escolar e é onde os gestores em conjunto com os professores terão que refletir as maneiras e como articular os conflitos que vierem acontecer. Sabemos que o ser humano não consegue viver só. Assim, a escola é composta desde a sua parte gestora por seres humanos, cada um com suas especificidades, então, ela jamais poderá manter-se somente com a comunidade escolar. Hoje, todo o educador necessita aprender a enfrentar novos desafios, pois não convivemos mais com uma sociedade tradicional, precisamos ir à busca de novos artifícios para poder estimular o aluno e para que não percamos o mesmo para a violência. 


\section{Referências}

ANTUNES, Helenise Sangoi. Imaginário social e formação inicial de professores: tecendo relações entre teorias e práticas educativas. In: ANTUNES, Helenise Sangoi (org.). Trajetória docente: o encontro da teoria com a prática. Santa Maria: UFSM, 2005, p. 1932.

BRASIL. Constituição da República Federativa do Brasil. Brasília: Senado Federal, 1988.

BRASIL. Lei n. 9.394/96, de 20 de dezembro de 1996. Estabelece as diretrizes e bases da educação nacional. Diário Oficial da União, Brasília, 23 dez. 1996. Disponível em <www.planalto.gov.br/ccivil_03/leis/L9394.htm>. Acesso em 25 jul. 2017.

BRASIL. Emenda Constitucional n. 59, de 11 de novembro de 2009. Diário Oficial da União, Poder Legislativo, Brasília, DF, 11 nov. 2009. Disponível em: <http://www.planalto.gov.br/ccivil_03/constituicao/

emendas/emc/emc59.htm>. Acesso em: 18 ago. 2017.

BRASIL. Lei no 13.005, de 24 de junho de 2014. Aprova o Plano Nacional de Educação PNE e dá outras providências. Diário Oficial da União, Poder Legislativo, Brasília, DF, 26 jun. 2014. Disponível em <http://www.planalto.gov.br/ccivil_03/_ato20112014/2014/lei//13005.htm>. Acesso em 7 jun. 2017.

BALZAN, Nilton César. Hei de vencer, mesmo sendo professor ou a introjeção da ética do dominador. Revista da Educação AEC, Brasília, v. 58, n. 14, 1985, p. 16-21.

BRUNO, Lúcia Emilia Nuevo Barreto. Poder e administração no capitalismo contemporâneo. In: OLIVEIRA, Dalila Andrade (org.). Gestão democrática da educação: desafios contemporâneos. Petrópolis: Vozes, 2008, p. 15-45.

CAMPOS, Maria Machado. Pesquisa participante: possibilidades para o estudo da escola. Cad. Pesq., São Paulo, n. 49, 1984, p. 63-66. Disponível em $<$ http://www.fcc.org.br/pesquisa/publicacoes/cp/arquivos/530.pdf>. Acesso em 20 out. 2017.

CATANI, Denice Barbara. Práticas de formação e ofício docente. In: BUENO, Belmira Oliveira.; CATANI, Denice Barbara.; SOUZA, Cynthia Pereira (orgs.). A vida e o ofício dos professores. São Paulo: Escrituras, 1998, p. 21-29.

CURY, Carlos Roberto Jamil. Os conselhos de educação e a gestão dos sistemas. In: FERREIRA, Naura Syria Carapeto; AGUIAR, Márcia Angela da Silva. (Orgs.). Gestão da educação: impasses, perspectivas e compromissos. São Paulo: Cortez, 2011, p. 43-60.

DESLAURIERS, Jean-Pierre.; KÉRISIT, Michele. O delineamento de pesquisa qualitativa. In: POUPART, Jean. et al. A pesquisa qualitativa: enfoques epistemológicos e metodológicos. Petrópolis: Vozes, 2008, p. 127-153.

DINIZ-PEREIRA, Júlio Emilio. Formação de professores: pesquisa, representações e poder. Belo Horizonte: Autêntica, 2000.

GUTIERREZ, Gustavo Luís; CATANI, Afrânio Mendes. Participação e gestão escolar: conceitos e potencialidades. In: FERREIRA, Naura Syria Carapeto (org.). Gestão democrática da educação: atuais tendências, novos desafios. São Paulo: Cortez, 2013, p. 75-94.

FLICK, Uwe. Introdução à pesquisa qualitativa. Porto Alegre: Artmed, 2009.

FREIRE, Paulo. Pedagogia da autonomia: saberes e fazeres necessários à prática educativa. Rio de Janeiro: Paz e Terra, 2014. 
GATTI, Bernardete Angelina. Diagnóstico, problematização e aspectos conceituais sobre a formação do magistério: subsídio para delineamento de políticas na área. São Paulo: FCC/DPE, 1996.

GATTI, Bernardete Angelina. Formação de professores e carreira: problemas e movimentos de renovação. Campinas: Autores associados, 2000.

GATTI, Bernardete Angelina. A formação inicial de professores para a educação básica: as licenciaturas. Revista USP, São Paulo, n. 100, p. 33-46, 2014. Disponível em <http://www.revistas.usp. br/revusp/article/view/76164/79909>. Acesso em 20 out. 2017.

LIBÂNEO, José Carlos. Democratização da escola pública: a pedagogia crítica-social dos conteúdos. São Paulo: Loyola, 1986.

LIBÂNEO, José Carlos. Pedagogia e pedagogos, para que? São Paulo: Cortez, 2004.

LIBÂNEO, José Carlos; OLIVEIRA, João Ferreira; TOSCHI, Mirza Seabra. Educação escolar: políticas, estrutura e organização. São Paulo: Cortez, 2007.

LÜCK, Heloísa. Dimensões da gestão escolar e suas competências. Curitiba: Positivo, 2009.

LÜCK, Heloísa. Gestão educacional: uma questão paradigmática. Petrópolis: Vozes, 2011.

MOITA, Maria da Conceição. Percursos de formação e de trans-formação. In: NÓVOA, Antonio Sampaio (org.). Vidas de professores. Porto: Porto, 1995, p. 111-140.

NÓVOA, Antonio Sampaio. Os professores e a sua formação. Lisboa: Dom Quixote, 1992.

SACRÍSTAN, José Gimeno. Consciência e ação sobre a prática como libertação profissional dos professores. In: NÓVOA, Antonio Sampaio (org.). Profissão professor. Porto: Porto, 1995, p. 63-92.

SANTA MARIA. Lei n. 4.740, de 24 de dezembro de 2003. Institui a gestão escolar democrática. Câmara de Vereadores de Santa Maria, RS, 24 dez. 2003. Disponível em <http://www.camara-sm.rs.gov.br/camara/proposicao/pesquisa/0/1/0/1227>. Acesso em 25 jul. 2017.

Maria Lúcia Leite da Silva é licenciada em Letras e Pedagogia, estudante do curso de Gestão Educacional, da Universidade Federal de Santa Maria.

Endereço: Rua Dr. Luiz Mallo, 2 - 97045-520 - Santa Maria - RS - Brasil.

E-mail: marialcial@yahoo.com.br.

Débora Ortiz Leão é professora adjunta na Universidade Federal de Santa Maria, doutora em Educação pela Pontifícia Universidade Católica do Rio Grande do Sul. Endereço: Avenida Roraima, 1000 - prédio 16 - 97105-900 - Santa Maria - RS Brasil.

E-mail: dboleao@gmail.com.

Recebido em 3 de junho de 2018.

Aceito em 16 de agosto de 2018.

(c) (i) 